\title{
Impact of non-pulmonary visceral metastases in the prognosis and practice of metastatic testicular germ cell tumors
}

\author{
Lorena Rossi, Filippo Martignano, Valentina Gallà, Antonio Maugeri, Giuseppe Schepisi \\ Istituto Scientifico Romagnolo per lo Studio e la Cura dei Tumori (IRST)-IRCCS, Meldola (FC), Italy
}

\begin{abstract}
Non-pulmonary visceral metastases, in bones, brain and liver, represent nearly the $10 \%$ of metastatic sites of advanced germ cell tumors and are associated with poor prognosis. This review article summarizes major evidences on the impact of different visceral sites on the prognosis, treatment and clinical outcome of patients with germ cell tumors. The clinic-biological mechanisms by which these metastatic sites are associated with poor clinical outcome remain unclear. The multimodality treatment showed a potential better survival, in particular in patients with relapsed disease. Patients with advanced germ cell tumors with visceral metastases should be referred to centers with high expertise in the clinical management of such disease.
\end{abstract}

\section{Introduction}

Testicular germ cell tumors (GCTs) are curable solid tumors thanks to the remarkable high chemosensitivity to platinum agents. ${ }^{1,2}$ There is a complex balance between the load of treatment, often concerning on platinum-based chemotherapy and the cure rate in GCT patients, because inappropriate systemic treatment can result in a low rate of cure, whereas the overtreatment may lead to acute and late adverse

Correspondence: Giuseppe Schepisi, Istituto Scientifico Romagnolo per lo Studio e la Cura dei Tumori (IRST)-IRCCS, via Maroncelli 40, 47014 Meldola (FC), Italy.

Tel.: +39.0543.739100 - Fax: +39.0543 .739290 .

E-mail: giuseppe.schepisi@irst.emr.it

Key words: Testicular cancer; germ cell tumor; chemotherapy; visceral metastases.

Contributions: all authors contributed to the production and approval of this manuscript.

Conflict of interest: the authors declare no potential conflict of interest.

Received for publication: 12 February 2016.

Accepted for publication: 7 April 2016.

This work is licensed under a Creative Commons Attribution NonCommercial 4.0 License (CC BY-NC 4.0).

(C) Copyright L. Rossi et al., 2016

Licensee PAGEPress, Italy

Oncology Reviews 2016; 10:292

doi:10.4081/oncol.2016.292 events. ${ }^{3-7}$ The proper staging of early and advanced disease can provide a more tailored approach to have an optimal treatment burden. ${ }^{3}$ Different factors can contribute to the prognosis of advanced GCT, including the primary and metastatic visceral sites, the type of histology (non-seminoma $v s$ seminoma) and the volume of disease expressed by the level of tumor markers: $\alpha$ fetoprotein (AFP), $\beta$-human chorionic gonadotropin ( $\beta \mathrm{HCG}$ ) and lactate dehydrogenase (LDH) ${ }^{8,9}$ In particular, primary mediastinal nonseminoma is characterized by a worse prognosis independently from other factors with resistance to standard-dose and high-dose chemotherapy in first-line setting and in relapsed patients. ${ }^{10-19}$ To date, the prognostic impact of visceral disease is well known, but it includes only brain, bone or liver metastases, while pulmonary localization in GCT patients does not belong to the definition of visceral metastases ${ }^{3,8,9}$ It is well established that patients with non-pulmonary visceral metastases have a poor prognosis; even recently larger retrospective analyses evaluated the impact of different metastatic sites on prognosis and treatment showing consistent differences within the different groups of metastatic visceral sites. This review article summarizes recent evidences on the impact of visceral disease in the prognosis of patients with advanced GCT.

\section{Prognostic models}

In advanced GCT patients, in first-line setting, the prognosis is determined by the International Germ Cell Cancer Collaborative Group (IGCCCG) classification. In this score system prognosis is associated with the presence or absence of nonpulmonary visceral metastases and, for nonseminomatous GCTs only, with the site of the primary tumor (testicular or retroperitoneal versus mediastinal) and with the levels of the serum tumor markers (Figure 1) ${ }^{20}$ In this staging score system, the number and diameter of the metastases had not a significant impact on multivariable analysis, whereas prognosis was predicted by the presence of metastases to sites other than the lungs and, for nonseminoma only, by the primary tumor site and the serum level of AFP, $\beta$ HCG and LDH. Based upon these factors, the IGCCCG classification subdivided GCT patients into good, intermediate, and poor prognosis groups. ${ }^{8}$ In this large retrospective analysis, the GCT patients received first-line cisplatin-based chemotherapy between 1975 and 1990; so several results were obtained in particular in the poor prognosis settings, treated with old regimens without the modern dose intensification. A recent meta-analysis has evaluated the prognosis in nearly 1800 patients with nonseminomatous GCT treated with first-line chemotherapy from 1989 to 2002 . It reported that five-year survival rate for the good- and intermediate-prognosis subsets were similar to those included in the IGCCCG study, but a 5-year overall survival rate of $71 \%$ versus $48 \%$ for poor-risk patients has been shown..$^{20} \mathrm{~A}$ better supportive care, including the use of granulocyte-colony stimulating factors, has allowed the correct dose intensity in poor prognosis patients. ${ }^{21-23}$ Moreover, a better management of post-chemotherapy 
residual masses with ameliorated imaging modalities and a use of referring institutions for surgical resection, have contributed to increase the cure rates of these patients. ${ }^{24-29}$ Lastly, the improved outcomes in poor prognosis patients are related to the better management of salvage treatments, including the use of multi-cycle high-dose chemotherapy in these patients, despite poor results in other solid tumors and the use of new chemotherapeutic agents. ${ }^{30-39}$ In patients progressing or relapsing after first-line therapy, a new scoring system has been recently validated. ${ }^{9}$ According to this scoring system visceral metastases (bone, brain or liver) could influence negatively the prognosis, even if mediastinal primary site remains the worst prognostic factor, in spite of the support of high-dose chemotherapy. ${ }^{9}$ However, it is necessary to distinguish among different organs of visceral metastases.

\section{Bone metastases}

The incidence of bone metastases is rare. In a retrospective series of 300 patients with GCT, bone metastases were found in 3\% of cases at initial presentation and in $9 \%$ at first relapse. ${ }^{40}$ Another study of 530 patients with GCTs, reported an incidence of $4 \%$ of bone metastases at relapse. ${ }^{41}$ Larger retrospective series on GCT late relapse ( $>3$ years after treatment) did not show bone metastases, so that bone is not a frequent site in late relapsing patients. ${ }^{42,43}$ The treatment of epidural spinal cord involvement showed improved survival when treated with chemotherapy only in a series of 29 cases. So the authors recommended platinum-based chemotherapy as the best therapy in patients with chemosensitive GCT presented with spinal cord involvement, whereas salvage chemotherapy and/or radiotherapy is suggested in platinumresistant GCT. ${ }^{44}$ Screening for bone metastases in patients with GCT is not generally recommended. A retrospective study of 434 poor prognosis patients treated with high-dose chemotherapy within two clinical trials identified 40 patients (9\%) with primary bone metastases, most commonly identified in patients with primary mediastinal tumors, yolk sac tumor histology, and synchronous liver metastases. ${ }^{45-47}$

A large study retrospectively analyzed prognostic factors and treatment of 114 GCT patients with bone metastases at first relapse, ${ }^{48}$ derived from a database containing 1594 patients (IPFSG study).$^{9}$ At relapse, 8 patients (8\%) had bone metastases only, 40 (39\%) concomitant lesions in the lung, 6 (6\%) in the brain, 27 (26\%)in the liver and/or $69(66 \%)$ in the lymph nodes. Salvage therapy consisted of standarddose chemotherapy in 35 cases and high-dose chemotherapy in 69 patients. Overall response rate was $81 \%$ after high-dose chemotherapy versus $43 \%$ after standard-dose chemotherapy $(\mathrm{P}<0.001)$, median progression-free survival was 9 months versus 5 months, respectively $(\mathrm{P}<0.01)$, and median overall survival was 18 months versus 13 months, respectively $(\mathrm{P}=0.078)$. The metastatic dissemination to bone marrow is very rare in $\mathrm{GCT}^{49}$ According to these retrospective data, high-dose chemotherapy seems a more appropriate option than conventional-dose chemotherapy for GCT patients in bone metastases.

\section{Good prognosis}

\begin{tabular}{|l|l} 
Non-seminoma (5-y PFS: 89\%, 5-y OS: 92\%) & $\begin{array}{l}\text { Seminoma (5-y PFS: 82\%, 5-y OS: 86\%) } \\
\text { any primary tumor location and }\end{array}$ \\
no extrapulmonary visceral metastases and & $\begin{array}{l}\text { no extrapulmonary visceral metastases and } \\
\text { AFP<1000, HCG }<5000 \text { and LDH<1.5xN }\end{array}$ \\
Normal AFP, any HCG or LDH
\end{tabular}

\section{Intermediate prognosis}

Non-seminoma (5-y PFS: 75\%, 5-y OS: 80\%)

gonadal or retroperitoneal primary site and

no extrapulmonary visceral metastases and

AFP $<10,000$, HCG $<50,000$ and $\mathrm{LDH}<10 \times \mathrm{N}$
Seminoma (5-y PFS: 67\%, 5-y OS: 72\%)

any primary tumor location

normal AFP, any HCG or LDH

and extrapulmonary visceral metastases

\section{Poor prognosis}

\begin{tabular}{|c|c|}
\hline Non-seminoma (5-y PFS: 41\%, 5-y OS: 48\%)* & Seminoma No patients \\
\hline $\begin{array}{l}\text { mediastinal primary tumor or } \\
\text { extrapulmonary visceral metastases or } \\
\mathrm{AFP}>\mathbf{1 0 , 0 0 0 ,} \mathrm{HCG}>\mathbf{5 0 , 0 0 0} \text { and } \mathrm{LDH}>\mathbf{1 0 x N}\end{array}$ & $\begin{array}{l}\text { * In the } 90 \text { 's the } 5 \text {-y OS in poor prognosis patients is } \\
\text { raised to } 60-65 \% \text { because of the use of G-CSF and better } \\
\text { management }{ }^{20}\end{array}$ \\
\hline
\end{tabular}

Figure 1. International Germ Cell Cancer Collaborative Group (IGCCCG) classification. PFS, progression-free survival; OS, overall survival; AFP, $\alpha$ fetoprotein; HCG, human chorionic gonadotropin; LDH, lactate dehydrogenase; G-CSF, granulocyte-colony stimulating factors. 
However, there is an urgent need to analyze a major number of GCT patients to determine the best chemotherapeutic approach. ${ }^{48,50}$ In the analysis of IGCCCG classification, bone metastases from pure seminoma are not associated with a poorer prognosis, but this data needs to be confirmed in larger series. ${ }^{8}$ To date, the data on bone metastases from GCT derived only from retrospective cohorts of 30-40 case $\mathrm{s}^{40-44}$ and from the IPFSG study data on 114 patients. ${ }^{9,47}$ Recently, the Global Germ cell cancer Group (G3), a consortium of GCT experts, has made a large international retrospective analysis aimed to identify the presence of significant factors related to prognosis and clinical outcome of these patients. The publication of these data is warranted to improve the knowledge of bone metastases from GCT.

\section{Brain metastases}

Approximately $2 \%$ to $3 \%$ of patients with advanced GCT develop brain metastases during their clinical history. ${ }^{51}$ Several small retrospective studies demonstrated a poor prognosis of these patients, but no further information was provided on clinical features or on the outcome or on the optimal management of these patients, even if multimodality treatment was considered as a treatment of choice in most of these series. ${ }^{51-58}$ The international consortium G3 collected data on 523 fully assessable patients with GCT and brain metastases at first diagnosis $(n=228)$ or at relapse $(n=295) .{ }^{59}$ In this analysis, brain metastases were associated with nonseminomatous GCT, with a high tumor burden, in particular pulmonary, liver or bone secondary localization, and with high HCG serum levels. The presence of brain metastases is more frequently related to higher tumor burden; however, it has been suggested that patients with brain metastases at initial diagnosis tend to present a better prognosis than previously treated patients. In the latter group, at the multivariate analysis, high-dose chemotherapy and multimodality treatment were the only factor associated with a better outcome. ${ }^{59}$

The negative impact of brain metastases in prognosis of GCT depends also on the addition of other risk factors. High-dose chemotherapy and multimodality treatment could prolong the survival of these patients..$^{53,59}$

\section{Liver metastases}

The liver represents the most common non-pulmonary visceral site in most of retrospective series in GCT with nearly $5-6 \%$ of cases presenting with visceral metastases at initial diagnosis. ${ }^{8,60,61}$ According to IGCCCG staging system and the evidences from other major retrospective series, patients with liver metastases could be classified as poor risk patients at initial presentation, representing about $20-25 \%$ of patients within the poor-risk group. , $^{8,90-62}$ Consequently, the poor prognosis associated with liver metastatic disease is related to an aggressive GCT and/or late diagnosis rather than a characteristic of liver involvement itself. Hepatic function alterations had no consequences and there were not even symptomatic complications of liver involvement for the management of these patients in terms of risks and benefits. ${ }^{60}$ GCT patients with liver metastases should be treated as a poor prognostic category at diagnosis and at relapse..$^{8,9}$

The impact of the resection of residual hepatic masses from nonseminomatous GCT after systemic therapy has been documented in many cases..$^{60,62-65}$ Even, retrospective data do not support the routine resection of all residual hepatic metastases persisting after initial approach to metastatic nonseminomatous GCT. Some authors recommended that hepatic resection should be indicated only for patients with residual liver masses from nonseminomatous GCT of more than 1 $\mathrm{cm}$ in diameter, when treatable. ${ }^{60,63}$ Anecdotic case reports are available on locoregional approaches, as internal radiation with yttrium-90 microspheres in the treatment of liver metastases. ${ }^{66}$

\section{Conclusions}

The incidence of visceral metastases is very low in patients with advanced GCT, but it is essential to consider them for the management of these patients, because they represent important prognostic factors. ${ }^{8,9}$ The biological mechanisms by which non-pulmonary visceral metastases are associated with a poor clinical outcome of GCT patients is not completely clear. Different hypotheses could be considered, including a poor penetration of chemotherapy due to specific microenvironment protection of tumor cells; ${ }^{67,68}$ inaccessibility to surgical resection of residual masses after chemotherapy ${ }^{69}$ and the fact that these metastatic sites are expression of a specific aggressive biology of these malignancies.

In the present review article, we have summarized data about the impact of visceral metastases from GCT mainly derived from retrospective series, with all limitations of this kind of analysis as selection and reporting prejudice, missing data, as well as different therapeutic approaches and regimens; nevertheless, prognostic factors and supports for decision making in different clinical settings have been presented and should be accounted. A multidisciplinary team for integrated approach including chemotherapy, high-dose chemotherapy, surgical approach, and radiotherapy may prolong the survival and reduce the costs and toxicity related to not appropriate treatments. Thus, patients with advanced GCT with visceral metastases should be referred to centers with high expertise in the clinical management of such disease.

\section{References}

1. Hanna NH, Einhorn LH. Testicular cancer-discoveries and updates. N Engl J Med 2014;371:2005-16.

2. Gori S, Porrozzi S, Roila F, et al. Germ cell tumours of the testis. Crit Rev Oncol Hematol 2005;53:141-64.

3. Beyer J, Albers P, Altena R, et al. Maintaining success, reducing treatment burden, focusing on survivorship: highlights from the third European consensus conference on diagnosis and treatment of germ-cell cancer. Ann Oncol 2013;24:878-88.

4. De Giorgi U, Nicolai N, Tana S, et al. IGG practice guidelines on germ cell tumor in adult male patients. Tumori 2008;94:96-109.

5. De Padova S, Rosti G, Scarpi E, et al. Italian Germ Cell Cancer Group (IGG). Expectations of survivors, caregivers and healthcare providers for testicular cancer survivorship and quality of life. Tumori 2011;97:367-73.

6. Oldenburg J, Aparicio J, Beyer J, et al. Personalizing, not patronizing: the case for patient autonomy by unbiased presentation of management options in stage I testicular cancer. Ann Oncol 2015; 26:833-8.

7. Travis LB, Beard C, Allan JM, et al. Testicular cancer survivorship: research strategies and recommendations. J Natl Cancer Inst 2010;102:1114-30.

8. [No authors listed]. International Germ Cell Consensus Classification: a prognostic factor-based staging system for metastatic germ cell cancers. International Germ Cell Cancer Collaborative Group. J Clin Oncol 1997;15:594-603.

9. International Prognostic Factors Study Group, Lorch A, Beyer J, et al. Prognostic factors in patients with metastatic germ cell tumors 
who experienced treatment failure with cisplatin-based first-line chemotherapy. J Clin Oncol. 2010;28:4906-11.

10. Bokemeyer C, Nichols CR, Droz JP, et al. Extragonadal germ cell tumors of the mediastinum and retroperitoneum: results from an international analysis. J Clin Oncol 2002;20:1864-73.

11. Schmoll HJ. Extragonadal germ cell tumors. Ann Oncol 2002;13:265-72.

12. Bokemeyer C, Hartmann JT, Fossa SD, et al. Extragonadal germ cell tumors: relation to testicular neoplasia and management options. APMIS 2003;111:49-59.

13. Rosti G, De Giorgi U, Wandt H, et al. First-line high-dose chemotherapy for patients with poor prognosis extragonadal germ cell tumors: the experience of the European Bone Marrow Transplantation (EBMT) Solid tumors working party. Bone Marrow Transplant 2004;34:1033-7.

14. Schneider BP, Kesler KA, Brooks JA, et al. Outcome of patients with residual germ cell or non-germ cell malignancy after resection of primary mediastinal nonseminomatous germ cell cancer. J Clin Oncol 2004;22:1195-200.

15. De Giorgi U, Demirer T, Wandt H, et al. Second-line high-dose chemotherapy in patients with mediastinal and retroperitoneal primary non-seminomatous germ cell tumors: the EBMT experience. Ann Oncol 2005;16:146-51.

16. Domínguez Malagón H, Pérez Montiel D. Mediastinal germ cell tumors. Semin Diagn Pathol 2005;22:230-40.

17. De Giorgi U, Rosti G, Slavin S, et al. Salvage high-dose chemotherapy for children with extragonadal germ-cell tumours. Br J Cancer 2005;93:412-7.

18. Banna GL, De Giorgi U, Ferrari B, et al. Is high-dose chemotherapy after primary chemotherapy a therapeutic option for patients with primary mediastinal nonseminomatous germ cell tumor? Biol Blood Marrow Transplant 2006;12:1085-91.

19. Albany C, Einhorn LH. Extragonadal germ cell tumors: clinical presentation and management. Curr Opin Oncol 2013;25:261-5.

20. van Dijk MR, Steyerberg EW, Habbema JD. Survival of non-seminomatous germ cell cancer patients according to the IGCC classification: An update based on meta-analysis. Eur J Cancer 2006;42:820-6.

21. Tanaka H, Yuasa T, Fujii Y, et al. First-line combination chemotherapy with cisplatin, etoposide and ifosfamide for the treatment of disseminated germ cell cancer: re-evaluation in the granulocyte colony-stimulating factor era. Chemotherapy 2013;59:441-6.

22. Fizazi K, Delva R, Caty A, et al. A risk-adapted study of cisplatin and etoposide, with or without ifosfamide, in patients with metastatic seminoma: results of the GETUG S99 multicenter prospective study. Eur Urol 2014;65:381-6.

23. Fizazi K, Pagliaro L, Laplanche A, et al. Personalised chemotherapy based on tumour marker decline in poor prognosis germ-cell tumours (GETUG 13): a phase 3, multicentre, randomised trial. Lancet Oncol 2014;15:1442-50.

24. De Giorgi U, Pupi A, Fiorentini G, et al. FDG-PET in the management of germ cell tumor. Ann Oncol 2005;16:iv90-4.

25. Hendry WF, A'Hern RP, Hetherington JW, et al. Para-aortic lymphadenectomy after chemotherapy for metastatic non-seminomatous germ cell tumors: prognostic value and therapeutic benefit. Br J Urol 1993;71:208-13.

26. Hartmann JT, Schmoll HJ, Kuczyk MA, et al. Postchemotherapy resections of residual masses from metastatic non-seminomatous testicular germ cell tumors. Ann Oncol 1997;8:531-8.

27. Fizazi K, Tjulandin S, Salvioni R, et al. Viable malignant cells after primary chemotherapy for disseminated nonseminomatous germ cell tumors: prognostic factors and role of postsurgery chemotherapy-results from an international study group. J Clin Oncol 2001;19:2647-57.

28. Beck SD, Foster RS, Bihrle R, et al. Outcome analysis for patients with elevated serum tumor markers at postchemotherapy retroperitoneal lymph node dissection. J Clin Oncol 2005;23:6149-56.

29. Fizazi K, Oldenburg J, Dunant A, et al. Assessing prognosis and optimizing treatment in patients with postchemotherapy viable nonseminomatous germ-cell tumors (NSGCT): results of the sCR2 international study. Ann Oncol 2008;19:259-64.

30. De Giorgi U, Rosti G, Papiani G, Marangolo M. The status of highdose chemotherapy with hematopoietic stem cell transplantation in germ cell tumor patients. Haematologica 2002;87:95-104.

31. Rosti G, De Giorgi U, Salvioni R, et al. Salvage high-dose chemotherapy in patients with germ cell tumors: an Italian experience with 84 patients. Cancer 2002;95:309-15.

32. Pedrazzoli P, Ferrante P, Kulekci A, et al. Autologous hematopoietic stem cell transplantation for breast cancer in Europe: critical evaluation of data from the European Group for Blood and Marrow Transplantation (EBMT) Registry 1990-1999. Bone Marrow Transplant 2003;32:489-94.

33. Kopf B, De Giorgi U, Vertogen B, et al. A randomized study comparing filgrastim versus lenograstim versus molgramostim plus chemotherapy for peripheral blood progenitor cell mobilization. Bone Marrow Transplant 2006;38:407-12.

34. Einhorn LH, Williams SD, Chamness A, et al. High-dose chemotherapy and stem-cell rescue for metastatic germ-cell tumors. N Engl J Med 2007;357:340-8.

35. De Giorgi U, Rosti G, Salvioni R, et al. Long-term outcome of salvage high-dose chemotherapy in patients with germ cell tumor with poor prognostic features. Urol Oncol 2011;29:284-90.

36. Lorch A, Bascoul-Mollevi C, Kramar A, et al. Conventional-dose versus high-dose chemotherapy as first salvage treatment in male patients with metastatic germ cell tumors: evidence from a large international database. J Clin Oncol 2011;29:2178-84.

37. De Giorgi U, Rosti G, Papiani G, et al. Weekly gemcitabine, paclitaxel, oxaliplatin combination chemotherapy in patients with cisplatin-refractory germ cell tumor: preliminary experience. Am J Clin Oncol 2004;27:457-60.

38. De Giorgi U, Rosti G, Aieta M, et al. Phase II study of oxaliplatin and gemcitabine salvage chemotherapy in patients with cisplatinrefractory nonseminomatous germ cell tumor. Eur Urol 2006;50:1032-8.

39. Oechsle K, Kollmannsberger C, Honecker F, et al. Long-term survival after treatment with gemcitabine and oxaliplatin with and without paclitaxel plus secondary surgery in patients with cisplatin-refractory and/or multiply relapsed germ cell tumors. Eur Urol 2011;850-5.

40. Hitchins RN, Philip PA, Wignall B, etal. Bone disease in testicular and extragonadal germ cell tumours. Br J Cancer 1988;58:793-6.

41. Gerl A, Clemm C, Schmeller N, et al. Late relapse of germ cell tumors after cisplatin-based chemotherapy. Ann Oncol 1997;8:41-7.

42. Jamal-Hanjani M, Karpathakis A, Kwan A, et al. Bone metastases in germ cell tumours: lessons learnt from a large retrospective study. BJU Int 2013;112:176-81.

43. Oldenburg J, Alfsen GC, Waehre H, Fossa SD. Late recurrences of germ cell malignancies: a population-based experience over three decades. Br J Cancer 2006;94:820-7.

44. Oechsle K, Bokemeyer C, Kollmannsberger C, etal. Bone metastases in germ cell tumor patients. J Cancer Res Clin Oncol 2012;138:947-52.

45. Bokemeyer C, Kollmannsberger C, Meisner C, etal. First-line highdose chemotherapy compared with standard-dose PEB/VIP chemotherapy in patients with advanced germ cell tumors: a multivariate and matched-pair analysis. J Clin Oncol 1999;17:3450-6.

46. Hartmann JT, Gauler T, Metzner B, et al. Phase I/II study of sequential dose-intensified ifosfamide, cisplatin, and etoposide plus paclitaxel as induction chemotherapy for poor prognosis germ cell 
tumors by the german testicular cancer study group. J Clin Oncol 2007;25:5742-7.

47. Oing C, Lorch A, Bokemeyer C, et al. First salvage treatment of germ cell tumor patients with bone metastases: retrospective analysis of a large international database. J Cancer Res Clin Oncol 2015;141:923-31.

48. Dazzi C, Cariello A, Rosti G, et al. Peripheral blood progenitor cell (PBPC) mobilization in heavily pretreated patients with germ cell tumors: a report of 34 cases. Bone Marrow Transplant 1999;23:529-32.

49. De Giorgi U, Papiani G, Severini G, et al. High-dose chemotherapy in adult patients with germ cell tumors. Cancer Control 2003;10:48-56.

50. Grommes C, Bosl GJ, DeAngelis LM. Treatment of epidural spinal cord involvement from germ cell tumors with chemotherapy. Cancer 2011;117:1911-6.

51. Bokemeyer C, Nowak P, Haupt A, et al. Treatment of brain metastases in patients with testicular cancer. J Clin Oncol 1997;15:1449-54.

52. Fossa SD, Bokemeyer C, Gerl A, et al. Treatment outcome of patients with brain metastases from malignant germ cell tumors. Cancer 1999;85:988-97.

53. Kollmannsberger C, Nichols C, Bamberg M, et al. First-line highdose chemotherapy $+/$ - radiation therapy in patients with metastatic germ cell cancer and brain metastases. Ann Oncol 2000;11:553-9.

54. Lutterbach J, Spetzger U, Bartelt S, et al. Malignant germ cell tumors metastatic to the brain: A model for a curable neoplasm? The Freiburg experience and a review of the literature. J Neurooncol 2002;58:147-56.

55. Nonomura N, Nagahara A, Oka D, et al. Brain metastases from testicular germ cell tumors: a retrospective analysis. Int J Urol 2009;16:887-93.

56. Boyle HJ, Jouanneau E, Droz JP, et al. Management of brain metastases from germ cell tumors: a single center experience. Oncology 2013;85:21-6.

57. Girones R, Aparicio J, Roure P, et al. Synchronous versus metachronous brain metastasis from testicular germ cell tumors (TGCT): an analysis from the spanish germ cell cancer group database. Clin Transl Oncol 2014;11:959-65.

58. Hardt A, Krell J, Wilson PD, et al. Brain metastases associated with germ cell tumors may be treated with chemotherapy alone. Cancer 2014;120:1639-46.

59. Feldman DR, Lorch A, Kramar A, et al. Brain metastases in patients with germ cell tumors: prognostic factors and treatment options-an analysis from the global germ cell cancer group. J Clin Oncol 2016;34:345-51.

60. Copson E, McKendrick J, Hennessey N, et al. Liver metastases in germ cell cancer: defining a role for surgery after chemotherapy. BJU Int 2004;94:552-8.

61. Sylvester R, Sleijfer DT. Multivariate analysis of prognostic factors in patients with disseminated non-seminomatous testicular cancer: results from an EORTC multi-institutional phase III study. Cancer Res 1987;47:2414-8.

62. Droz JP, Kramar A, Ghosn M, et al. Prognostic factors in advanced non-seminomatous testicular cancer. Cancer 1988;62:564-8.

63. Hahn T, Jacobson L, Einhorn L, et al. Hepatic resection of metastatic testicular carcinoma: a further update. Ann Surg Oncol 1999;6:640-4.

64. Rivoire M, Elias D, De Cian F, et al. Multimodality treatment of patients with liver metastases from germ cell tumors: the role of surgery. Cancer 2001;92:578-87.

65. Hartmann JT, Rick 0, Oechsle K, et al. Role of postchemotherapy surgery in the management of patients with liver metastases from germ cell tumors. Ann Surg 2005;242:260-6.

66. Sideras PA, Sofocleous CT, Brody LA, et al. Superselective internal radiation with yttrium-90 microspheres in the management of a chemorefractory testicular liver metastasis. Cardiovasc Intervent Radiol 2012;35:426-9.

67. James PB, Mead GM. Sanctuary site relapse in chemotherapy-treated testicular cancer. Ann Oncol 1992;3:41-3.

68. De Giorgi U. Is high-dose chemotherapy based on carboplatin, a late dose-intensification of a cisplatin-based salvage chemotherapy in germ cell tumour patients? Ann Oncol 2006;17:530-1.

69. Stenning SP, Parkinson HC, Fisher C, et al. Post-chemotherapy residual masses in germ cell tumour patients. Cancer 1998;83:1409-19. 